\title{
Bone density as a marker for local response to radiotherapy of spinal bone metastases in women with breast cancer: a retrospective analysis
}

Robert Foerster ${ }^{1}$, Christian Eisele ${ }^{1}$, Thomas Bruckner ${ }^{2}$, Tilman Bostel ${ }^{1}$, Ingmar Schlampp ${ }^{1}$, Robert Wolf ${ }^{1}$, Juergen Debus ${ }^{1}$ and Harald Rief ${ }^{1 *}$

\begin{abstract}
Background: We designed this study to quantify the effects of radiotherapy (RT) on bone density as a local response in spinal bone metastases of women with breast cancer and, secondly, to establish bone density as an accurate and reproducible marker for assessment of local response to RT in spinal bone metastases.

Methods: We retrospectively assessed 135 osteolytic spinal metastases in 115 women with metastatic breast cancer treated at our department between January 2000 and January 2012. Primary endpoint was to compare bone density in the bone metastases before, 3 months after and 6 months after RT. Bone density was measured in Hounsfield units $(\mathrm{HU})$ in computed tomography scans. We calculated mean values in $\mathrm{HU}$ and the standard deviation (SD) as a measurement of bone density before, 3 months and 6 months after RT. T-test was used for statistical analysis of difference in bone density as well as for univariate analysis of prognostic factors for difference in bone density 3 and 6 months after RT.

Results: Mean bone density was $194.8 \mathrm{HU} \pm$ SD 123.0 at baseline. Bone density increased significantly by a mean of $145.8 \mathrm{HU} \pm$ SD 139.4 after 3 months $(p=.0001)$ and by $250.3 \mathrm{HU} \pm$ SD 147.1 after 6 months $(p<.0001)$. Women receiving bisphosphonates showed a tendency towards higher increase in bone density in the metastases after 3 months (152.6 HU \pm SD 141.9 vs. $76.0 \mathrm{HU} \pm$ SD 86.1; $p=.069$ ) and pathological fractures before RT were associated with a significantly higher increase in bone density after 3 months (202.3 HU \pm SD 161.9 vs. $130.3 \mathrm{HU} \pm$ SD 129.2; $p=.013$ ). Concomitant chemotherapy (ChT) or endocrine therapy (ET), hormone receptor status, performance score, applied overall RT dose and prescription of a surgical corset did not correlate with a difference in bone density after RT.

Conclusions: Bone density measurement in $\mathrm{HU}$ is a practicable and reproducible method for assessment of local RT response in osteolytic metastases in breast cancer. Our analysis demonstrated an excellent local response within metastases after palliative RT.
\end{abstract}

Keywords: Bone density, Bone metastases, Breast cancer, Radiotherapy, Local response

\footnotetext{
* Correspondence: harald.rief@med.uni-heidelberg.de

'Department of Radiation Oncology, University Hospital Heidelberg,

Im Neuenheimer Feld 400, 69120 Heidelberg, Germany

Full list of author information is available at the end of the article
} 


\section{Background}

The bone is the most common site for metastases in women with breast cancer [1]. Bone metastases of the spinal column are a major cause of morbidity and reduced quality of life due to severe pain, pathological fractures, spinal cord compression and hypercalcemia $[2,3]$. Bone metastases require a multimodal treatment approach including radiotherapy (RT), minimal invasive surgery and systemic treatments such as bisphosphonates [4]. RT is the most common treatment method $[5,6]$, and its indications are typically pain, instability or neurological symptoms due to spinal cord compression [7]. The simultaneous delivery of RT and bisphosphonates may be beneficial for re-ossification of the bone affected by osseous metastases [8-10]. Previously we were able to show that RT is capable of promoting reossification leading to increased stability of spinal bone metastases [11-13]. Secondly, in a recent trial we were able to show that the quantification of bone density within metastases was an accurate and practicable method to evaluate local response after RT [14]. The aim of our current analysis was to quantify the effects of RT on bone density in the metastatic bone in breast cancer patients with spinal bone metastases and to establish bone density as a marker for assessment of local response to RT.

\section{Methods}

We retrospectively assessed 135 osteolytic metastases of the thoracic and lumbar vertebral column treated with RT at our department between January 2000 and January 2012. The spinal bone metastases were found in 115 women with metastatic breast cancer. Patients' data were collected from the local cancer registry. Median age was 60 years (range 32-88) and median Karnofsky performance status (KPS) was $80 \%$ at first presentation. Seventy-six patients (56.3\%) had more than one spinal bone metastasis. Cases characteristics are shown in Table 1. The cases selected for this study were those with available minimum follow-up computed tomography (CT) scans for 3 months after RT. For patients that underwent RT for several regions, each irradiated region was regarded separately as an individual case and in each region only the metastasis with the highest degree of instability according to Taneichi et al. was included in our study [15]. The primary endpoint of this study was to compare bone density in the irradiated metastasis before RT and 3 months as well as 6 months after RT. Additionally we performed a reference measurement of the bone density in the neighboring irradiated vertebral body which was not affected by bone metastases. Most patients were treated additionally with bisphosphonates during RT (91.1\%), which represents a major bias for the assessment of treatment response in
Table 1 Cases characteristics

\begin{tabular}{|c|c|c|}
\hline \multicolumn{3}{|l|}{ Age } \\
\hline Median & 60 years & \\
\hline \multirow[t]{2}{*}{ Range } & $32-88$ years & \\
\hline & $\mathrm{n}$ & $\%$ \\
\hline \multicolumn{3}{|c|}{ Karnofsky performance status } \\
\hline $30-70 \%$ & 40 & $29.6 \%$ \\
\hline $80-90 \%$ & 95 & $70.3 \%$ \\
\hline \multicolumn{3}{|l|}{ Histology } \\
\hline Invasive ductal & 107 & $79.3 \%$ \\
\hline Invasive lobular & 28 & $20.7 \%$ \\
\hline \multicolumn{3}{|c|}{ Receptor status positivity } \\
\hline ER $(N=34)$ & 28 & $82.4 \%$ \\
\hline $\operatorname{PgR}(N=50)$ & 40 & $80.0 \%$ \\
\hline HER2 ( $N=135)$ & 39 & $28.9 \%$ \\
\hline \multicolumn{3}{|l|}{ Site } \\
\hline Thoracic & 99 & $73.3 \%$ \\
\hline Lumbar & 36 & $26.7 \%$ \\
\hline \multicolumn{3}{|c|}{ Number of bone metastases } \\
\hline Solitary & 59 & $43.7 \%$ \\
\hline Multiple & 76 & $56.3 \%$ \\
\hline \multicolumn{3}{|c|}{ Treatment indications } \\
\hline Pain & 69 & $51.1 \%$ \\
\hline Instability & 44 & $32.6 \%$ \\
\hline \multicolumn{3}{|c|}{ Pathological fracture } \\
\hline Before RT & 29 & $21.5 \%$ \\
\hline After RT & 8 & $5.9 \%$ \\
\hline \multicolumn{3}{|l|}{ Surgical corset } \\
\hline During RT & 82 & $60.7 \%$ \\
\hline
\end{tabular}

the metastasis. Therefore, a bone density measurement of uninvolved vertebral bodies was executed to detect the increase by a systemic treatment. Bone density was assessed in Hounsfield units (HU) by manual region of interest (ROI) setting of the whole vertebral body for uninvolved bone and within metastases for involved bone (Figure 1). The study was approved by the university's ethical committee (\# S-513/2012).

\section{Radiotherapy}

RT was planned as virtual simulation based on planning CT imaging and was delivered over a dorsal 6 MV photon filed. The planning target volume (PTV) covered the affected vertebral bodies as well as the ones directly above and below. Median prescribed total dose was $30.0 \mathrm{~Gy}$ in 3.0 Gy single fractions. Treatment characteristics are shown in Table 2. 

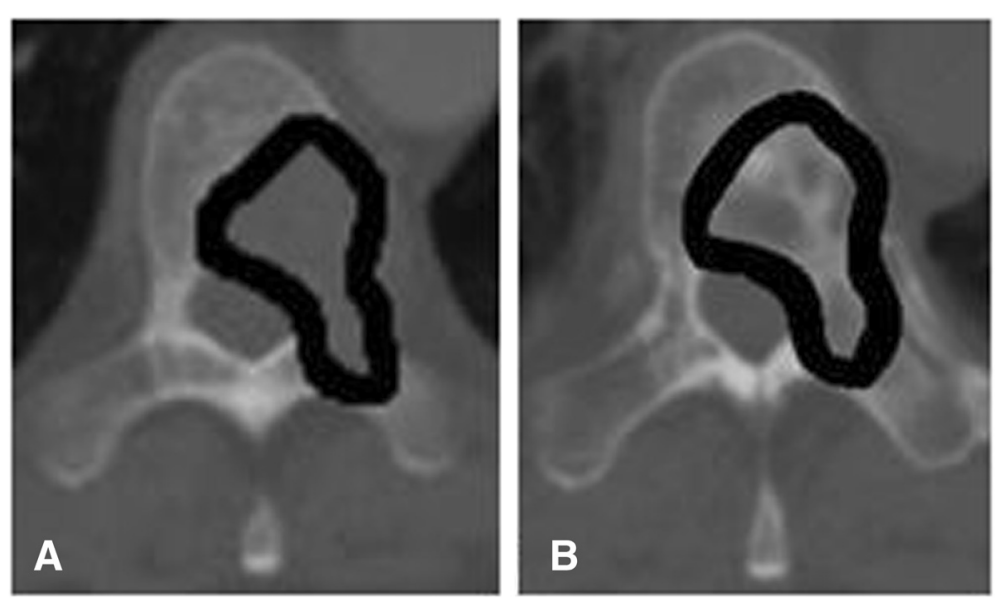

Figure 1 Osteolytic thoracic spinal metastasis (A) before RT and (B) 3 months after RT as a basis for bone density measurement in HU by manual ROI setting.

\section{Statistical analysis}

We calculated mean values in $\mathrm{HU}$ and the standard deviation (SD) as a measurement for bone density before as well as 3 and 6 months after RT. Regarding statistical analysis of difference in bone density as well as for univariate analysis of prognostic factors for difference in bone density at 3 and at 6 months after RT we calculated the equality of variances and used the $t$-test. As possible prognostic factors we investigated systemic therapy (chemotherapy (ChT) and endocrine therapy (ET)) before/after RT, bisphosphonates after RT, treatment indications (pain, stability), prescription of a surgical corset, irradiated area (lumbar vs. thoracic), number of metastases ( 1 vs. >1), prescribed overall RT dose, pathological fractures before/after $\mathrm{RT}$ and hormone receptor status (estrogen (ER), progesterone (PgR), Her-2/ neu (HER2)). A p-value $\leq 0.05$ was considered statistically

Table 2 Treatment of cases

\begin{tabular}{lll}
\hline & $\mathbf{n}$ & $\%$ \\
\hline Radiotherapy (RT) $(\mathbf{N}=\mathbf{1 3 3})$ & 77 & \\
$10 \times 3 \mathrm{~Gy}$ & 20 & $15.1 \%$ \\
$14 \times 2.5 \mathrm{~Gy}$ & 34 & $25.6 \%$ \\
$20 \times 2$ Gy & 2 & $1.5 \%$ \\
Others & & \\
Systemic therapy prior to $\mathbf{R T}$ & 46 & $34.1 \%$ \\
Chemotherapy & 47 & $34.8 \%$ \\
Endocrine therapy & 51 & $37.8 \%$ \\
Bisphosphonates & & \\
Systemic therapy after RT & 72 & $53.3 \%$ \\
Chemotherapy & 26 & $86.7 \%$ \\
Endocrine therapy $(\mathrm{N}=30)$ & 123 & $91.1 . \%$ \\
Bisphosphonates &
\end{tabular}

significant. All statistical analyses were performed with SAS software 9.1 (SAS Institute, Cary, NC, USA).

\section{Results}

The mean calculated size of the metastases was $431.3 \mathrm{~mm}^{2} \pm$ SD 313.5 and the mean bone density in the metastases was 194.8 HU \pm SD 123.0 at initial assessment. Three months after RT we observed a mean bone density of $340 \mathrm{HU} \pm \mathrm{SD} 179.2$ and after 6 months a mean bone density of $433.1 \mathrm{HU} \pm$ SD 172.6 in the metastases. Whereas mean bone density in the irradiated unaffected neighboring vertebral bodies was $235.9 \mathrm{HU} \pm$ SD 143.4 before RT, 228.6 HU \pm SD 143.2 after 3 months and 250.3 HU \pm SD 147.1 after 6 months. Bone density increased significantly in the metastases during followup after RT. At 3 months the bone density had increased by a mean of $145.8 \mathrm{HU} \pm$ SD $139.4(\mathrm{p}<.0001)$ and after 6 months by a mean of $238.0 \mathrm{HU} \pm$ SD 149.2 ( $<<.0001)$. The bone density in the irradiated unaffected neighboring vertebral bodies used for reference measurements did not change significantly during follow-up after RT.

Table 3 Bone density (HU) in metastases and in irradiated uninvolved bone

\begin{tabular}{lcllll}
\hline & Mean & SD & Mean difference & SD & p-value \\
\hline Bone metastases & \multicolumn{5}{l}{} \\
Before RT & 194.8 & 123.0 & & & \\
After 3 months & 340.6 & 179.2 & 145.8 & 139.4 & $\mathrm{p}<.0001$ \\
After 6 months & 433.1 & 172.6 & 238.0 & 149.2 & $\mathrm{p}<.0001$
\end{tabular}

Irradiated

uninvolved bone

\begin{tabular}{llllll} 
Before RT & 235.9 & 143.4 & & & \\
After 3 months & 228.6 & 143.2 & -7.3 & -1.41 & $p=.162$ \\
After 6 months & 250.3 & 147.1 & -0.1 & -0.01 & $p=.993$ \\
\hline
\end{tabular}


Table 4 Univariate analysis of prognostic factors for difference in bone density in HU

\begin{tabular}{|c|c|c|c|c|c|c|c|c|}
\hline & \multicolumn{4}{|c|}{ After 3 months } & \multicolumn{4}{|c|}{ After 6 months } \\
\hline & $n$ & Mean & SD & p-value & $\mathrm{n}$ & Mean & SD & p-value \\
\hline Bisphosphonates after RT & & & & $p=.069$ & & & & $p=.162$ \\
\hline Yes & 123 & 152.6 & 141.9 & & 76 & 245.8 & 151.5 & \\
\hline No & 12 & 76.0 & 86.1 & & 9 & 171.9 & 114.4 & \\
\hline Pathological fracture before RT & & & & $p=.013$ & & & & $p=.801$ \\
\hline Yes & 29 & 202.3 & 161.9 & & 21 & 230.8 & 141.7 & \\
\hline No & 106 & 130.3 & 129.2 & & 64 & 240.3 & 152.6 & \\
\hline Pathological fracture after RT & & & & $p=.399$ & & & & $p=.399$ \\
\hline Yes & 8 & 186.3 & 133.6 & & 8 & 280.5 & 135.3 & \\
\hline No & 127 & 143.2 & 139.9 & & 77 & 233.5 & 150.7 & \\
\hline Chemotherapy before RT & & & & $p=.946$ & & & & $p=.991$ \\
\hline Yes & 46 & 144.7 & 135.3 & & 23 & 238.3 & 172.9 & \\
\hline No & 89 & 146.4 & 148.6 & & 62 & 237.8 & 140.9 & \\
\hline Chemotherapy after RT & & & & $p=.741$ & & & & $p=.547$ \\
\hline Yes & 72 & 149.5 & 130.9 & & 45 & 247.2 & 144.9 & \\
\hline No & 63 & 141.5 & 149.5 & & 40 & 227.5 & 154.9 & \\
\hline Endocrine therapy before RT & & & & $p=.211$ & & & & $p=.133$ \\
\hline Yes & 47 & 125.2 & 137.3 & & 25 & 200.2 & 136.1 & \\
\hline No & 88 & 156.8 & 140.1 & & 60 & 253.7 & 152.6 & \\
\hline Endocrine therapy after RT & & & & $p=.536$ & & & & $p=.657$ \\
\hline Yes & 26 & 121.9 & 98.1 & & 17 & 196.3 & 143.6 & \\
\hline No & 4 & 87.8 & 125.4 & & 2 & 250.0 & 316.8 & \\
\hline Pain as indication for RT & & & & $p=.822$ & & & & $p=.963$ \\
\hline Yes & 69 & 148.5 & 141.5 & & 46 & 238.7 & 143.3 & \\
\hline No & 66 & 143.0 & 138.3 & & 39 & 237.1 & 157.7 & \\
\hline Instability as indication for RT & & & & $p=.479$ & & & & $p=.554$ \\
\hline Yes & 91 & 139.9 & 133.9 & & 57 & 231.2 & 141.9 & \\
\hline No & 44 & 158.1 & 150.9 & & 28 & 251.7 & 164.8 & \\
\hline Surgical corset & & & & $p=.358$ & & & & $p=.213$ \\
\hline Yes & 82 & 136.9 & 134.9 & & 52 & 221.8 & 144.6 & \\
\hline No & 53 & 159.6 & 146.3 & & 33 & 263.4 & 154.9 & \\
\hline Spine & & & & $p=.437$ & & & & $p=.858$ \\
\hline Thoracic & 99 & 150.7 & 149.1 & & 65 & 239.6 & 155.9 & \\
\hline Lumbar & 36 & 132.3 & 109.2 & & 20 & 232.7 & 128.1 & \\
\hline Number of metastases & & & & $p=.983$ & & & & $p=.382$ \\
\hline 1 & 59 & 146.1 & 132.4 & & 35 & 254.9 & 158.2 & \\
\hline$>1$ & 76 & 145.6 & 145.5 & & 50 & 226.1 & 142.9 & \\
\hline Overall dose & & & & $p=.886$ & & & & $p=.654$ \\
\hline$<=30 \mathrm{~Gy}$ & 79 & 145.1 & 130.9 & & 57 & 229.6 & 143.8 & \\
\hline$>30$ Gy & 54 & 141.6 & 150.8 & & 26 & 245.6 & 162.9 & \\
\hline KPS & & & & $\mathrm{p}=.815$ & & & & $p=.412$ \\
\hline$</=70 \%$ & 40 & 150.1 & 148.1 & & 23 & 263.4 & 259.9 & \\
\hline$>70 \%$ & 95 & 143.9 & 136.4 & & 62 & 228.5 & 163.7 & \\
\hline
\end{tabular}


Table 4 Univariate analysis of prognostic factors for difference in bone density in HU (Continued)

\begin{tabular}{|c|c|c|c|c|c|c|c|c|}
\hline Estrogen receptor status & & & & $p=.278$ & & & & $p=.828$ \\
\hline Positive & 28 & 139.9 & 115.2 & & 19 & 222.5 & 156.6 & \\
\hline Negative & 6 & 83.8 & 99.3 & & 2 & 250.0 & 316.8 & \\
\hline Progesterone receptor status & & & & $p=.088$ & & & & $p=.694$ \\
\hline Positive & 40 & 159.9 & 123.5 & & 25 & 242.7 & 149.5 & \\
\hline Negative & 10 & 87.8 & 83.4 & & 4 & 276.5 & 214.5 & \\
\hline Her-2/neu receptor status & & & & $p=.581$ & & & & $p=.379$ \\
\hline Positive & 39 & 156.3 & 118.4 & & 28 & 220.2 & 108.2 & \\
\hline Negative & 96 & 141.5 & 147.5 & & 57 & 246.7 & 165.8 & \\
\hline
\end{tabular}

After 3 months we found a slight decrease by a mean of $-7.3 \mathrm{HU} \pm \mathrm{SD} 60.4(\mathrm{p}=.162)$ and after 6 months, with a mean decrease of $-0.1 \mathrm{HU} \pm \mathrm{SD} 70.1 \quad(\mathrm{p}=.993)$, there was practically no change in bone density observable (Table 3).

Increase in bone density of the metastases seemed to be associated with the prescription of bisphosphonates. While women receiving bisphosphonates had a mean increase in bone density of $152.59 \mathrm{HU} \pm$ SD 141.99 in the metastases after 3 months, patients without bisphosphonates only had a mean increase in bone density of $76.03 \mathrm{HU} \pm$ SD $86.6(\mathrm{p}=.069)$ in the metastases 3 months following RT. Additionally we found that women with pathological fractures before RT (21.5\%) had a significantly higher increase in bone density after 3 months than those which presented without fractures at initial assessment (202.3 HU \pm SD 161.88 vs. $130.33 \mathrm{HU} \pm$ SD $129.23 ; \mathrm{p}=.013)$. These differences were no longer detectable 6 months after RT. All other investigated potentially prognostic factors, especially concomitant ChT or ET, hormone receptor status, KPS, applied overall dose as well as the prescription of a surgical corset, did not significantly correlate with an increase or decrease in bone density after RT (Table 4).

\section{Discussion}

In previous studies we demonstrated that RT is capable of improving stability in spinal bone metastases by facilitating re-ossification [11-14]. With our current analysis we were able to quantify the re-ossification after RT by measuring the change in mean bone density on the basis of $\mathrm{x}$-ray absorption in $\mathrm{CT}$ scans and we found that mean bone density, as a local response, increased significantly in the metastases after RT. While mean bone density in the metastases increased by $145.8 \mathrm{HU} \pm$ SD 139.4 after 3 months $(\mathrm{p}<.0001)$ and by $238.0 \mathrm{HU} \pm$ SD 149.2 after 6 months $(\mathrm{p}<.0001)$, this was not the case in the irradiated neighboring vertebrae unaffected by bone metastases. Other investigators found bone density to increase after RT as well [16,17]. Currently local response is chiefly assessed by visual judgment of sclerosis of the osteolytic lesions in $\mathrm{CT}$ scans, with complete response being classified as complete sclerosis of the metastasis, partial response as $>50 \%$ regression of the metastasis and no response as an unchanged metastases [18]. Such an evaluation of local treatment response is very subjective and imprecise. We believe bone density measurement to be a more reliable and reproducible method for assessment and quantification of re-ossification as a local response to RT in osteolytic spinal bone metastases.

Clinical and preclinical studies suggest a benefit from combined treatment with systemic bisphosphonates concomitant to RT [19-21] since they have been shown to exhibit cytotoxic and radiosensitizing effects when combined with RT additional to their anti-bone-resorptive properties [22,23]. In our analysis there was a strong tendency towards statistical significance for increased bone density in the metastases with concomitant bisphosphonate treatment 3 months following RT $(\mathrm{p}=.069)$ and after 6 months the mean increase in mean bone density was still larger in patients receiving combination treatment compared to those without bisphosphonates (245.8 HU \pm SD 151.5 vs. 171.9 HU \pm SD 114.4). Nevertheless, the rate of bisphosphonates was high (91.1\%). However, this was not the case for the irradiated bone unaffected by metastases. We believe that bisphosphonates may be capable of facilitating RT effects in bone metastases and that these patients may respond more rapidly. Other concomitant systemic treatments in the form of ChT or ET did not affect bone density in our analysis. Similarly, systemic treatment before/after RT did not influence local response in terms of stability in two earlier studies [12,13]. This is probably due to the fact that most patients in our study were already postmenopausal and did received bisphosphonates which was not the case in another previous study where ChT before RT had a negative effect on stability as a local response to RT [11]. Negative effects on bone density by aromatase inhibitors [24] and disturbances in bone remodeling by ChT [25] may have been compensated by concomitant bisphosphonate therapy, tamoxifen treatment probably had a rather bone-protective effect [26] and ChT- 
associated ovarian failure [27] did not play a relevant role in our cohort.

Furthermore we found that mean bone density increase after 3 months was significantly higher in patients with pathological fractures at initial assessment $(\mathrm{p}=.013)$ which can be explained by physiological consolidation processes with callus formation after acute fractures. Nevertheless, pathological fracture may affect the bone density in sintered vertebral body after treatment, but this bias was insignificant small in $5.9 \%$ of patients.

We found no statistically significant correlation between the remaining investigated prognostic factors and an increase or decrease in bone density after RT. Koswig and Budach found bone density after 6 months to have increased by $173 \%$ after 30 Gy in 10 fractions compared to $120 \%$ after a single fraction of $8 \mathrm{~Gy}$ [16]. Most women in our analysis were treated with an overall dose of 30 Gy in 3 Gy single fractions and thus we were unable to detect any differences between fractionation schedules. KPS and the prescription of a surgical corset also did not affect response to RT in terms of bone density although a higher KPS and not wearing a surgical corset should in theory be associated with more physical activity which in turn can lead to an improved stability of spinal bone metastases $[11,14]$.

\section{Conclusions}

Bone density increased significantly in the metastases during follow-up after RT, while practically no change was seen in the irradiated bone unaffected by metastases. Bone density measurement in $\mathrm{HU}$ is a reliable and reproducible method for assessment of local response in osteolytic metastases after RT. Concomitant bisphosphonate may protect from bone-resorptive effects induced by ChT and ET.

\section{Competing interests}

The authors declare that they have no competing interests.

\section{Authors' contributions}

RF and HR designed the study. RF and CE were responsible for data collection and interpretation of the results. TB performed the statistical analysis. RF drafted the manuscript. All authors critically revised and approved the final version of the manuscript.

\section{Acknowledgement}

We acknowledge the financial support of Deutsche Forschungsgemeinschaft and Ruprecht-Karls-Universität Heidelberg within the funding program Open Access Publishing.

\section{Author details}

'Department of Radiation Oncology, University Hospital Heidelberg, Im Neuenheimer Feld 400, 69120 Heidelberg, Germany. ${ }^{2}$ Department of Medical Biometry, University Hospital Heidelberg, Im Neuenheimer Feld 305, 69120 Heidelberg, Germany.

Received: 12 February 2015 Accepted: 24 February 2015

Published online: 07 March 2015

\section{References}

1. Lutz S, Berk L, Chang E, Chow E, Hahn C, Hoskin P, et al. Palliative radiotherapy for bone metastases: an ASTRO evidence-based guideline. Int J Radiat Oncol Biol Phys. 2011:79:965-76.

2. Whyne CM, Hu SS, Lotz JC. Biomechanically derived guideline equations for burst fracture risk prediction in the metastatically involved spine. J Spinal Disord Tech. 2003;16:180-5.

3. Janjan N, Lutz ST, Bedwinek JM, Hartsell WF, Ng A, Pieters Jr RS, et al. Therapeutic guidelines for the treatment of bone metastasis: a report from the American College of Radiology Appropriateness Criteria Expert Panel on Radiation Oncology. J Palliat Med. 2009;12:417-26.

4. Chow E, Zeng L, Salvo N, Dennis K, Tsao M, Lutz S. Update on the systematic review of palliative radiotherapy trials for bone metastases. Clin Oncol (R Coll Radiol). 2012;24:112-24.

5. Mitera G, Probyn L, Ford M, Donovan A, Rubenstein J, Finkelstein J, et al. Correlation of computed tomography imaging features with pain response in patients with spine metastases after radiation therapy. Int J Radiat Oncol Biol Phys. 2011;81:827-30.

6. Wu JS, Monk G, Clark T, Robinson J, Eigl BJ, Hagen N. Palliative radiotherapy improves pain and reduces functional interference in patients with painful bone metastases: a quality assurance study. Clin Oncol (R Coll Radiol). 2006;18:539-44.

7. Souchon R, Feyer $P$, Thomssen C, Fehm T, Diel I, Nitz U, et al. Clinical Recommendations of DEGRO and AGO on Preferred Standard Palliative Radiotherapy of Bone and Cerebral Metastases, Metastatic Spinal Cord Compression, and Leptomeningeal Carcinomatosis in Breast Cancer. Breast Care (Basel). 2010;5:401-7.

8. Oda I, Abumi K, Lu D, Shono Y, Kaneda K. Biomechanical role of the posterior elements, costovertebral joints, and rib cage in the stability of the thoracic spine. Spine (Phila Pa 1976). 1996:21:1423-9.

9. Oster G, Lamerato L, Glass AG, Richert-Boe KE, Lopez A, Chung K, et al. Natural history of skeletal-related events in patients with breast, lung, or prostate cancer and metastases to bone: a 15-year study in two large US health systems. Support Care Cancer. 2013;21:3279-86.

10. Weber MH, Burch S, Buckley J, Schmidt MH, Fehlings MG, Vrionis FD, et al. Instability and impending instability of the thoracolumbar spine in patients with spinal metastases: a systematic review. Int J Oncol. 2011;38:5-12.

11. Foerster R, Habermehl D, Bruckner T, Bostel T, Schlampp I, Welzel T, et al. Spinal bone metastases in gynecologic malignancies: a retrospective analysis of stability, prognostic factors and survival. Radiat Oncol. 2014;9:194.

12. Rief H, Bischof M, Bruckner T, Welzel T, Askoxylakis V, Rieken S, et al. The stability of osseous metastases of the spine in lung cancer-a retrospective analysis of 338 cases. Radiat Oncol. 2013;8:200.

13. Schlampp I, Rieken S, Habermehl D, Bruckner T, Forster R, Debus J, et al. Stability of spinal bone metastases in breast cancer after radiotherapy: a retrospective analysis of 157 cases. Strahlenther Onkol. 2014;190:792-7.

14. Rief H, Petersen LC, Omlor G, Akbar M, Bruckner T, Rieken S, et al. The effect of resistance training during radiotherapy on spinal bone metastases in cancer patients - A randomized trial. Radiother Oncol. 2014;112(1):133-9.

15. Taneichi H, Kaneda K, Takeda N, Abumi K, Satoh S. Risk factors and probability of vertebral body collapse in metastases of the thoracic and lumbar spine. Spine (Phila Pa 1976). 1997;22:239-45.

16. Koswig S, Budach V. Remineralization and pain relief in bone metastases after after different radiotherapy fractions (10 times 3 Gy vs. 1 time 8 Gy). A prospective study. Strahlenther Onkol. 1999;175:500-8.

17. Chow E, Holden L, Rubenstein J, Christakis M, Sixel K, Vidmar M, et al. Computed tomography (CT) evaluation of breast cancer patients with osteolytic bone metastases undergoing palliative radiotherapy-a feasibility study. Radiother Oncol. 2004;70:291-4.

18. Xie CM, Liu XW, Li H, Zhang R, Mo YX, Li JP, et al. Computed tomographic findings of skull base bony changes after radiotherapy for nasopharyngeal carcinoma: implications for local recurrence. J Otolaryngol Head Neck Surg. 2011;40:300-10.

19. Krempien R, Huber PE, Harms W, Treiber M, Wannenmacher M, Krempien B. Combination of early bisphosphonate administration and irradiation leads to improved remineralization and restabilization of osteolytic bone metastases in an animal tumor model. Cancer. 2003;98:1318-24.

20. Ural AU, Avcu F, Baran Y. Bisphosphonate treatment and radiotherapy in metastatic breast cancer. Med Oncol. 2008;25:350-5.

21. Kouloulias V, Matsopoulos G, Kouvaris J, Dardoufas C, Bottomley A, Varela M, et al. Radiotherapy in conjunction with intravenous infusion of $180 \mathrm{mg}$ of 
disodium pamidronate in management of osteolytic metastases from breast cancer: clinical evaluation, biochemical markers, quality of life, and monitoring of recalcification using assessments of gray-level histogram in plain radiographs. Int J Radiat Oncol Biol Phys. 2003;57:143-57.

22. Ural AU, Avcu F, Candir M, Guden M, Ozcan MA. In vitro synergistic cytoreductive effects of zoledronic acid and radiation on breast cancer cells. Breast Cancer Res. 2006:8:R52.

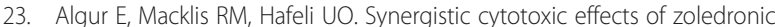
acid and radiation in human prostate cancer and myeloma cell lines. Int J Radiat Oncol Biol Phys. 2005;61:535-42.

24. Eastell R, Adams JE, Coleman RE, Howell A, Hannon RA, Cuzick J, et al. Effect of anastrozole on bone mineral density: 5-year results from the anastrozole, tamoxifen, alone or in combination trial 18233230. J Clin Oncol. 2008;26:1051-7.

25. Lustberg MB, Reinbolt RE, Shapiro CL. Bone health in adult cancer survivorship. J Clin Oncol. 2012;30:3665-74.

26. Love RR, Mazess RB, Barden HS, Epstein S, Newcomb PA, Jordan VC, et al. Effects of tamoxifen on bone mineral density in postmenopausal women with breast cancer. N Engl J Med. 1992;326:852-6.

27. Shapiro CL, Manola J, Leboff M. Ovarian failure after adjuvant chemotherapy is associated with rapid bone loss in women with early-stage breast cancer. J Clin Oncol. 2001:19:3306-11.

\section{Submit your next manuscript to BioMed Central and take full advantage of:}

- Convenient online submission

- Thorough peer review

- No space constraints or color figure charges

- Immediate publication on acceptance

- Inclusion in PubMed, CAS, Scopus and Google Scholar

- Research which is freely available for redistribution 